\title{
Volumetric Properties of Some Aliphatic Mono- and Dicarboxylic Acids in Water at 298.15 K
}

\author{
Adam Bald · Zdzisław Kinart
}

Received: 17 February 2010 / Accepted: 24 June 2010 / Published online: 20 November 2010

(C) The Author(s) 2010. This article is published with open access at Springerlink.com

\begin{abstract}
The apparent molar volumes, $V_{\phi}$, of two series of homologous aliphatic carboxylic acids, $\mathrm{H}\left(\mathrm{CH}_{2}\right)_{n} \mathrm{COOH}[n=0-5]$ and $\left(\mathrm{CH}_{2}\right)_{n}(\mathrm{COOH})_{2}[n=0-5]$, were determined in dilute aqueous solutions by density measurements at $T=298.15 \mathrm{~K}$. Densities were measured using a vibrating-tube densimeter (DMA 5000, Anton Paar, Austria) at $T=298.15 \mathrm{~K}$. These results were used to calculate the apparent molar volumes of each solute over the concentration range $0.0050 \leq \mathrm{m} /\left(\mathrm{mol} \cdot \mathrm{kg}^{-1}\right) \leq 0.3000$. Values of the apparent molar volumes of undissociated acids $V_{\phi(u)}^{0}$ were also calculated. The variation of $V_{\phi(u)}^{0}$ was determined as a function of the aliphatic chain length of the studied carboxylic acids.
\end{abstract}

Keywords Carboxylic acid · Apparent molar volume · Water

\section{Introduction}

In this paper, we report results on the effect of increasing the size of the hydrophobic side chain of homologous aliphatic mono- and dicarboxylic acids on the physicochemical properties of these electrolytes in aqueous solutions, which is part of a wider study [1-4]. Knowledge of the thermodynamic properties of aqueous solutions of acids and bases and their reactions provides many useful insights with theoretical and practical applications. The carboxylic acids are used in the production of polyester polyols, polyamides, ester plasticizers, in the synthesis of pharmaceuticals, and have applications as corrosion inhibitors, surfactants and metal finishing compounds.

Volumetric studies of carboxylic acids provide great help in characterizing the structure and properties of their solutions, which are important in understanding the nature of action of these bioactive molecules and their interactions in the human body. A review of the literature

\footnotetext{
A. Bald $\cdot$ Z. Kinart $(\bowtie)$

Department of Physical Chemistry of Solutions, University of Lodz, ul. Pomorska 163, 90-236 Lodz, Poland

e-mail: zkinart@uni.lodz.pl
}

A. Bald

e-mail: laurent@uni.lodz.pl 
shows that only a few authors have attempted to determine values of the apparent molar volumes of carboxylic acids in water [5-15].

Therefore, the purpose of the present study is to determine the density, apparent molar volume, and apparent molar volume at infinite dilution, and the limiting partial molar volume of carboxylic acids of the types $\mathrm{H}\left(\mathrm{CH}_{2}\right)_{n} \mathrm{COOH}[n=0-5]$ and $\left(\mathrm{CH}_{2}\right)_{n}(\mathrm{COOH})_{2}[n=0-5]$ in water at $T=298.15 \mathrm{~K}$.

\section{Experimental}

\subsection{Materials}

The sources of chemicals and methods of purification were described in our previous papers [1-4]. Water was passed through an ion exchanger and then distillated. The specific conductivity of this purified water was less than $0.8 \times 10^{-6} \Omega^{-1} \cdot \mathrm{cm}^{-1}$.

\subsection{Apparatus and Procedures}

The densities of solutions were measured using a vibrating-tube digital densimeter (Model DMA 5000, Anton Paar, Austria) with a precision of $\pm 1 \times 10^{-6} \mathrm{~g} \cdot \mathrm{cm}^{-3}$ and an accuracy of $\pm 5 \times 10^{-6} \mathrm{~g} \cdot \mathrm{cm}^{-3}$. The temperature of the water around the densimeter cell was controlled to $\pm 0.001 \mathrm{~K}$. The densimeter was calibrated periodically with dry air and pure water.

The solutions were prepared by adding weighed amounts of the concentrated stock solutions into a cell containing a known amount of pure water. All of the solutions were prepared by mass using an analytical balance (Sartorius RC 210D) with an uncertainty of $\pm 1 \times 10^{-5} \mathrm{~g}$.

\section{Results and Discussion}

The densities $(\rho)$ of solutions of the studied carboxylic acids at $T=298.15 \mathrm{~K}$ are given as a function of concentration in Table 1. From the measured densities the apparent molar volumes $\left(V_{\phi}\right)$, were calculated by using the following equation:

$$
V_{\phi}=\left[\frac{1000\left(\rho_{0}-\rho\right)}{m \rho_{0} \rho}\right]+\frac{M_{\mathrm{w}}}{\rho}
$$

where $V_{\phi}$ is the apparent molar volume, $m$ is the molality, $M_{\mathrm{w}}$ is the molecular weight of the carboxylic acid, and $\rho_{0}$ and $\rho$ are the densities of water and of the solution, respectively. The values of $V_{\phi}$ as a function of concentration of electrolyte are summarized in Tables 1a and $1 b$.

The dependence $V_{\phi}$ as the function of the concentration for strong electrolytes can be described by the Redlich-Rosenfeld equation [16, 17]:

$$
V_{\phi}=V_{\phi}^{0}+S_{v} \sqrt{c}+b_{v} c
$$

where: $V_{\phi}^{0}$ is the limiting apparent molar volume, $S_{v}$ is the theoretical limiting slope, $b_{v}$ is an empirical constant determined from experimental results, and $c$ is the molar concentration. The value of $S_{v}$ for aqueous solutions of 1:1 and 2:1 type electrolytes at $298.15 \mathrm{~K}$ are equal, respectively, to 1.868 and $9.706 \mathrm{~cm}^{3} \cdot \mathrm{dm}^{3 / 2} \cdot \mathrm{mol}^{-3 / 2}[16,17]$. 
Table 1a Apparent molar volumes $\left(V_{\phi}\right)$, molarity $(c)$, molality $(m)$, and degree of dissociation $\beta$ of solutions of aliphatic monocarboxylic acids in water at $298.15 \mathrm{~K}$

\begin{tabular}{|c|c|c|c|c|}
\hline $\begin{array}{l}c \\
\left(\mathrm{~mol} \cdot \mathrm{dm}^{-3}\right)\end{array}$ & $\begin{array}{l}m \\
\left(\mathrm{~mol} \cdot \mathrm{kg}^{-1}\right)\end{array}$ & $\begin{array}{l}\rho \\
\left(\mathrm{g} \cdot \mathrm{cm}^{-3}\right)\end{array}$ & $\begin{array}{l}V_{\phi} \\
\left(\mathrm{cm}^{3} \cdot \mathrm{mol}^{-1}\right)\end{array}$ & $\beta$ \\
\hline
\end{tabular}

Formic acid

0

$0.04001 \quad 0.04018$

0.997043

\subsection{4}

0.07897

0.09912

0.11912

0.13871

0.15870

0.17791

0.19774

0.21773

0.23719

0.25697

0.27623

0.29592

0.05965

0.07943

0.09977

0.11999

0.13983

0.16010

0.17960

0.19976

0.22012

0.23996

0.26016

0.27986

0.30003

0.997443

0.997626

36.13

$-$

$0.997815-36.36$

$0.998011 \quad 36.37$

$0.998202 \quad 36.40$

$0.998392 \quad 36.41$

$0.998586 \quad 36.41$

$0.998773 \quad 36.41$

$0.998964 \quad 36.42$

$0.999156 \quad 36.43$

$0.999344 \quad 36.43$

$0.999534 \quad 36.44$

$0.999720 \quad 36.44$

$0.999908 \quad 36.45$

0.069265

0.057574

0.050337

0.045230

0.041478

0.038606

0.036233

0.034334

0.032666

0.031217

0.029984

0.028874

0.027907

0.027017

Acetic acid

0

0.03980

0

0.05943

0.04001

0.997043

0.997377

51.81

0.07906

0.05980

0.997524

52.11

0.997678

52.17

0.09902

0.07962

0.997834

52.22

0.11871

0.11980

0.997990

52.23

0.998146

52.25

0.998298

0.15998

0.998448

52.27

52.30

$0.998598 \quad 52.33$

0.20015

0.998744

52.35

0.998897

52.36

0.23635

0.21972

0.999046

52.37

0.27513

0.25984

0.29452

0.27996

0.999204

52.35

0.29999

0.999350

52.37

0.021468

0.017664

0.015375

0.013780

0.012617

0.011701

0.010974

0.010371

0.009852

0.009421

0.009030

0.008693

0.008388

0.008116

Propionic acid

$$
0
$$

$0.01960 \quad 0.01969$

0.997043

0.997183

67.13

$-$

$0.03861 \quad 0.03883$

0.997301

67.60

0.026508

$0.05960 \quad 0.06002$

0.997430

67.78

0.019051

0.07863

0.07928

0.997549

67.84

0.015417

0.09916

0.10013

0.997679

67.86

0.013469

0.11867

0.11999

0.997802

67.88

0.012028

0.011020

0.010233

0.009594

0.15772

0.13987

0.009060

0.17740

0.18009

0.998172

67.91

0.008611

0.21632

0.20021

0.998295

67.92

0.008227

0.23803

0.24266

67.93

0.007853 
Table 1a (Continued)

\begin{tabular}{lllll}
\hline $\begin{array}{l}c \\
\left(\mathrm{~mol} \cdot \mathrm{dm}^{-3}\right)\end{array}$ & $\begin{array}{l}\rho \\
\left(\mathrm{mol} \cdot \mathrm{kg}^{-1}\right)\end{array}$ & $\begin{array}{l}V_{\phi} \\
\left(\mathrm{g} \cdot \mathrm{cm}^{-3}\right)\end{array}$ & $\beta$ \\
\hline 0.25480 & 0.26006 & 0.998660 & 67.93 & 0.007597 \\
0.27383 & 0.27985 & 0.998780 & 67.94 & 0.007336 \\
0.29315 & 0.30000 & 0.998901 & 67.94 & 0.007097
\end{tabular}

Butyric acid

0

0.02007

0

0.03996

0.05961

0.07975

0.09938

0.11867

0.13674

0.15732

0.17659

0.19737

0.21605

0.23475

0.25384

0.27263

0.29155

Valeric acid

0.00958

0.02009

0.03875

0.05948

0.07909

0.09857

0.11831

0.13770

0.15682

0.17636

0.19555

Caproic acid

0

0.01666

0.03330

0.04980

0.06634

0.08249

0.11704

0.13867

0.15595

0.17646

0.19500
0

0.00962

0.02019

0.03901

0.06001

0.07996

0.09985

0.12008

0.14004

0.15979

0.18006

0.20004

0

0.01674

0.03352

0.05023

0.06705

0.08353

0.11899

0.14135

0.15928

0.18067

0.20009
0.997043

0.997068

0.997091

0.997127

0.997169

0.997208

0.997246

0.997284

0.997318

0.997358

0.997397

0.997433

99.81

100.03

100.25

100.30

100.34

100.37

100.39

100.43

100.42

100.42

100.43

0.997043

0.997061

0.997073

0.997084

0.997095

0.997105

0.997127

0.997140

0.997150

0.997163

0.997175

115.41

115.59

115.67

115.71

115.74

115.78

115.80

115.81

115.82

115.82
0.027770 0.019860 0.016344 0.014183 0.012742 0.011688 0.010909 0.010189 0.009632 0.009125 0.008733 0.008388 0.008075 0.007800 0.007550 0.038048 0.026554 0.019280 0.015654 0.013615 0.012230 0.011190 0.010392 0.009755 0.009213 0.008761

0.027743
0.019793
0.016264
0.014140
0.012714
0.010720
0.009869
0.009320
0.008776
0.008359


Table 1b Apparent molar volumes $\left(V_{\phi}\right)$, molarity $(c)$, molality $(m)$, and fractions $\left(\beta_{1}, \beta_{2}\right)$ of solutions of aliphatic dicarboxylic acids in water, at $298.15 \mathrm{~K}$

\begin{tabular}{llllll}
\hline $\begin{array}{l}c \\
\left(\mathrm{~mol} \cdot \mathrm{dm}^{-3}\right)\end{array}$ & $\begin{array}{l}\rho \\
\left(\mathrm{mol} \cdot \mathrm{kg}^{-1}\right)\end{array}$ & $\begin{array}{l}V_{\phi} \\
\left(\mathrm{g} \cdot \mathrm{cm}^{-3}\right)\end{array}$ & $\begin{array}{l}\beta_{1} \\
\left(\mathrm{~cm}^{3} \cdot \mathrm{mol}^{-1}\right)\end{array}$ & & $\beta_{2}$ \\
\hline Oxalic acid & & & & & - \\
0 & 0 & 0.997043 & - & - & 0.656714 \\
0.05957 & 0.05992 & 0.999610 & 47.08 & 0.614268 & 0.001886 \\
0.07941 & 0.07994 & 1.000434 & 47.47 & 0.581477 & 0.001288 \\
0.09898 & 0.09975 & 1.001251 & 47.66 & 0.554155 & 0.001124 \\
0.11899 & 0.12003 & 1.002095 & 47.72 & 0.531559 & 0.001004 \\
0.13875 & 0.14009 & 1.002926 & 47.78 & 0.512800 & 0.000914 \\
0.15782 & 0.15950 & 1.003726 & 47.83 & 0.495534 & 0.000837 \\
0.17794 & 0.18000 & 1.004567 & 47.89 & 0.480701 & 0.000776 \\
0.19752 & 0.19999 & 1.005384 & 47.95 & 0.467581 & 0.000726 \\
0.21687 & 0.21980 & 1.006189 & 48.00 & 0.456455 & 0.000685 \\
0.23499 & 0.23838 & 1.006946 & 48.03 & 0.444791 & 0.000644 \\
0.25588 & 0.25984 & 1.007816 & 48.08 & 0.434806 & 0.000611 \\
0.27549 & 0.28002 & 1.008633 & 48.11 & 0.425811 & 0.000582 \\
0.29467 & 0.29980 & 1.009433 & 48.13 & &
\end{tabular}

Malonic acid

\begin{tabular}{|c|c|c|c|c|c|}
\hline 0 & 0 & 0.997043 & - & - & - \\
\hline 0.04062 & 0.04085 & 0.998583 & 66.34 & 0.183795 & 0.000072 \\
\hline 0.05955 & 0.05996 & 0.999298 & 66.39 & 0.155864 & 0.000051 \\
\hline 0.07936 & 0.08001 & 1.000048 & 66.39 & 0.137529 & 0.000039 \\
\hline 0.09895 & 0.09990 & 1.000790 & 66.39 & 0.124836 & 0.000032 \\
\hline 0.11862 & 0.11992 & 1.001534 & 66.40 & 0.115252 & 0.000028 \\
\hline 0.13818 & 0.13988 & 1.002274 & 66.40 & 0.107732 & 0.000024 \\
\hline 0.15753 & 0.15967 & 1.003001 & 66.44 & 0.101657 & 0.000021 \\
\hline 0.17750 & 0.18015 & 1.003758 & 66.43 & 0.096412 & 0.000019 \\
\hline 0.19687 & 0.20007 & 1.004489 & 66.44 & 0.092075 & 0.000018 \\
\hline 0.21632 & 0.22013 & 1.005226 & 66.43 & 0.088297 & 0.000016 \\
\hline 0.23565 & 0.24011 & 1.005954 & 66.44 & 0.084996 & 0.000015 \\
\hline 0.25483 & 0.25998 & 1.006687 & 66.41 & 0.082085 & 0.000014 \\
\hline 0.27387 & 0.27977 & 1.007416 & 66.38 & 0.079491 & 0.000013 \\
\hline 0.29327 & 0.29997 & 1.008161 & 66.35 & 0.077102 & 0.000013 \\
\hline \multicolumn{6}{|c|}{ Succinic acid } \\
\hline 0 & 0 & 0.997043 & - & - & - \\
\hline 0.03959 & 0.03984 & 0.998460 & 82.54 & 0.097455 & 0.000077 \\
\hline 0.05948 & 0.05995 & 0.999171 & 82.55 & 0.080841 & 0.000052 \\
\hline 0.07932 & 0.08008 & 0.999877 & 82.60 & 0.070783 & 0.000040 \\
\hline 0.09893 & 0.10004 & 1.000575 & 82.63 & 0.063908 & 0.000033 \\
\hline 0.11856 & 0.12009 & 1.001272 & 82.66 & 0.058768 & 0.000028 \\
\hline 0.13815 & 0.14016 & 1.001968 & 82.68 & 0.054746 & 0.000024 \\
\hline 0.15727 & 0.15981 & 1.002646 & 82.70 & 0.051551 & 0.000022 \\
\hline 0.17688 & 0.18004 & 1.003343 & 82.71 & 0.048815 & 0.000019 \\
\hline 0.19628 & 0.20010 & 1.004031 & 82.73 & 0.046514 & 0.000018 \\
\hline 0.21554 & 0.22010 & 1.004714 & 82.74 & 0.044536 & 0.000016 \\
\hline 0.23463 & 0.23998 & 1.005393 & 82.74 & 0.042815 & 0.000015 \\
\hline
\end{tabular}


Table 1b (Continued)

\begin{tabular}{llllll}
\hline $\begin{array}{l}c \\
\left(\mathrm{~mol} \cdot \mathrm{dm}^{-3}\right)\end{array}$ & $\begin{array}{l}\rho \\
\left(\mathrm{mol} \cdot \mathrm{kg}^{-1}\right)\end{array}$ & $\begin{array}{l}\rho \\
\left(\mathrm{g} \cdot \mathrm{cm}^{-3}\right)\end{array}$ & $\begin{array}{l}V_{\phi} \\
\left(\mathrm{cm}^{3} \cdot \mathrm{mol}^{-1}\right)\end{array}$ & $\beta_{1}$ & $\beta_{2}$ \\
\hline 0.25383 & 0.26004 & 1.006076 & 82.74 & 0.041280 & 0.000014 \\
0.27292 & 0.28004 & 1.006754 & 82.75 & 0.039915 & 0.000013 \\
0.29258 & 0.30072 & 1.007454 & 82.75 & 0.038646 & 0.000012
\end{tabular}

Glutaric acid

0

0.03932

0.05905

0.07893

0.09846

0.11824

0.13745

0.15696

0.17602

0.19558

0.21497

0.23393

0.25295

0.27163

0.29034

Adipic acid

0

0.02011

0.03967

0.05942

0.07910

0.09881

0.11795

0.13739

0.15669

0.17548

0.18411

Pimelic acid

0

0.02994

0.04949

0.06910

0.08963

0.09845

0.11788

0.12756

0.14689

0.16581

0.17539

0.18469

0.19440

0
0.03959
0.05957
0.07978
0.09972
0.11999
0.13975
0.15990
0.17966
0.20003
0.22028
0.24016
0.26020
0.27994
0.29980

0

0.02021

0.03997

0.06002

0.08013

0.10028

0.11998

0.14009

0.16013

0.17975

0.18879

\section{0}

0.03014

0.04996

0.06994

0.09097

0.10004

0.12009

0.13013

0.15024

0.17002

0.18009

0.18988

0.20013
0.997043

0.998375

0.999036

0.999702

1.000352

1.001014

1.001662

1.002310

1.002948

1.003599

1.004250

1.004877

1.005509

1.006135

1.006760

0.997043

0.997666

0.998272

0.998879

0.999483

1.000086

1.000666

1.001259

1.001849

1.002420

1.002680

0.997043

0.997915

0.998482

0.999047

0.999637

0.999890

1.000450

1.000727

1.001283

1.001823

1.002095

1.002361

1.002640
98.53

98.65

98.71

98.80

98.82

98.80

98.85

98.86

98.89

98.88

98.92

98.94

98.93

98.94

115.49

115.51

115.59

115.66

115.70

115.78

115.81

115.83

115.86

115.88

131.42

131.49

131.55

131.61

131.64

131.65

131.68

131.70

131.73

131.76

131.76

131.77

$\begin{array}{ll}- & - \\ 0.034677 & 0.000113 \\ 0.028529 & 0.000077 \\ 0.024817 & 0.000058 \\ 0.022315 & 0.000047 \\ 0.020435 & 0.000040 \\ 0.019009 & 0.000034 \\ 0.017834 & 0.000030 \\ 0.016879 & 0.000027 \\ 0.016045 & 0.000025 \\ 0.015334 & 0.000023 \\ 0.014724 & 0.000021 \\ 0.014181 & 0.000019 \\ 0.013705 & 0.000018 \\ 0.013274 & 0.000017\end{array}$

- 0.043184

0.000214

0.031173

0.000112

0.000076

0.000058

0.000047

0.000040

0.000034

0.000030

0.000027

0.015235

0.000026

0.014887

\begin{tabular}{ll}
- & - \\
0.032812 & 0.000144 \\
0.025759 & 0.000089 \\
0.021929 & 0.000065 \\
0.019342 & 0.000050 \\
0.018486 & 0.000046 \\
0.016948 & 0.000039 \\
0.016314 & 0.000036 \\
0.015241 & 0.000032 \\
0.014376 & 0.000028 \\
0.013991 & 0.000027 \\
0.013647 & 0.000025 \\
0.013314 & 0.000024 \\
\hline
\end{tabular}


In the case of weak electrolytes such as mono and dicarboxylic acids, Eq. 2 must be modified. For the studied monocarboxylic acids (HA) Eq. 2 adopts the following form:

$$
V_{\phi}=\beta V_{\mathrm{HA}(i)}+(1-\beta) V_{\mathrm{HA}(u)}
$$

where: $V_{\mathrm{HA}(i)}$ is the apparent molar volume of the acid in its dissociated form, and $V_{\mathrm{HA}(u)}$ is the apparent molar volume of the acid in the undissociated form.

$$
\begin{aligned}
& V_{\mathrm{HA}(i)}=V_{\mathrm{HA}(i)}^{0}+S_{v} \sqrt{\beta c}+b_{v i} \beta c \\
& V_{\mathrm{HA}(u)}=V_{\mathrm{HA}(u)}^{0}+b_{v u}(1-\beta) c
\end{aligned}
$$

The values of $\beta$ can be calculated by optimization using:

$$
K_{\mathrm{A}}=\frac{1}{K_{\mathrm{D}}}=\frac{1-\beta}{\beta^{2} c y_{ \pm}^{2}}, \quad \ln y_{ \pm}=\frac{-A_{\mathrm{DH}} \sqrt{\beta c}}{1+R_{y} B_{\mathrm{DH}} \sqrt{\beta c}}
$$

where $y_{ \pm}$is the molarity-based activity coefficient, $A_{\mathrm{DH}}$ and $B_{\mathrm{DH}}$ are coefficients defined by the Debye-Hückel limiting law; for water at $298.15 \mathrm{~K}, A_{\mathrm{DH}}=1.1727 \mathrm{~mol}^{-1 / 2} \cdot \mathrm{dm}^{3 / 2}$ and $B_{\mathrm{DH}}=0.3286 \times 10^{8} \mathrm{~mol}^{-1 / 2} \cdot \mathrm{dm}^{3 / 2} \cdot \mathrm{cm}^{-1}$. The values of $R_{y}$ were assumed to be equal to $q=3.58 \times 10^{-8} \mathrm{~cm}$ (the Bjerrum distance). The $\beta$ coefficients can be determined from values of the association constants $K_{\mathrm{A}}$ reported in the literature [18]. Calculated values of $\beta$ are collected in Table 1a.

Equation 3, after talking into consideration Eqs. 4 and 5, assumes the following form:

$$
V_{\phi}=\beta\left(V_{\mathrm{HA}(i)}^{0}+S_{v(i)} \sqrt{\beta c}+b_{v(i)} \beta c\right)+(1-\beta)\left\{V_{\mathrm{HA}(u)}^{0}+b_{v(u)}(1-\beta) c\right\}
$$

A similar approach was applied by King [5] for the analysis of the apparent molar volumes of monocarboxylic acids. However, King transformed Eq. 6 into the following form:

$$
V_{\phi}-\beta \Delta V^{0}-\beta S_{v(i)} \sqrt{\beta c}=V_{\mathrm{HA}(u)}^{0}+b_{v(i)} \beta^{2} c+b_{v(u)}(1-\beta)^{2} c
$$

where

$$
\Delta V^{0}=V_{\mathrm{HA}(i)}^{0}-V_{\mathrm{HA}(u)}^{0}
$$

King [5] assumed that component terms $\beta \Delta V^{0}, \beta S_{v(i)} \sqrt{\beta c}$ and $b_{v(i)} \beta^{2} c$ are small enough to treat the left side of the Eq. $6 \mathrm{~b}$ as being linearly dependent on $(1-\beta)^{2} c$. On the basis of this assumption, he estimated values of $V_{\mathrm{HA}(u)}^{0}$ and $b_{v(u)}$ for formic, acetic and butyric acids. A similar method was applied by Høiland [6] for estimation of $V_{\mathrm{H}_{2} \mathrm{~A}(u)}^{0}$ and $b_{v(u)}$ for dicarboxylic acids $\left(\mathrm{CH}_{2}\right)_{n}(\mathrm{COOH})_{2}$ with $n=0-5$.

A different procedure proposed by King [5] has been applied in this work. Assuming that: $S_{v(i)}=1.868[16,17]$ :

$$
\begin{aligned}
& V_{\mathrm{HA}(i)}=V_{\mathrm{NaA}(i)}^{0}+\left(V_{\mathrm{H}^{+}}^{0}-V_{\mathrm{Na}^{+}}^{0}\right) \\
& V_{\mathrm{H}^{+}}^{0}-V_{\mathrm{Na}^{+}}^{0}=1.2 \mathrm{~cm}^{3} \cdot \mathrm{mol}^{-1}
\end{aligned}
$$

Then Eq. 6a assumes the following form:

$$
V_{\phi}=\beta V_{\mathrm{HA}(i)}^{0}+1.868 \beta \sqrt{\beta c}+b_{v(i)} \beta^{2} c+(1-\beta) V_{\mathrm{HA}(u)}^{0}+b_{v(u)}(1-\beta)^{2} c
$$


Values of $V_{\mathrm{NaA}}^{0}$ were reported in our previous work [19] whereas $V_{\mathrm{HA}(u)}^{0}, b_{v u}$ and $b_{v(i)}$ of Eq. 7 are unknowns.

The dependences of the separate terms of Eq. 7 on the concentration are shown for formic $(n=0)$ and caproic $(n=5)$ acids in Figs. $1 \mathrm{a}$ and $1 \mathrm{~b}$, and the numerical values of these terms are presented in Tables $3 \mathrm{a}$ and $3 \mathrm{~b}$. The $\beta^{2} c b_{v(i)}$ term was omitted since its value is smaller than the experimental error.

As shown at Fig. 1 and Table 3, the values of the apparent molar volumes of the acids are practically affected only by the $\beta V_{\mathrm{HA}(i)}^{0}$ and $(1-\beta) V_{\mathrm{HA}(u)}^{0}$ terms. The impact of $(1-$ $\beta)^{2} c b_{v(u)}$ is definitely smaller. In the case of the higher monocarboxylic acids for which the values of $\beta$ are smaller, this conclusion is more certain.

The values $V_{\mathrm{HA}(u)}^{0}$ and $b_{v(u)}$ were obtained using a nonlinear least-squares method and they are reported in Table 2. The $V_{\phi(u)}^{0}$ results given in Table 2 for monocarboxylic acids correlate well with results reported by King [5] and Hamman [8]. Only for formic acid, and to a lesser degree for acetic acid, is this correlation worse. Values for valeric $(n=4)$ and caproic $(n=5)$ acids have been determined for the first time.

The dependence of $V_{\phi}^{0}=f(n)$ is shown in Fig. 2. This plot is linear with a slope equal to 15.88 for $n=0-5$. For $n=0$ there is no alkyl group in the studied molecule and there is only one $-\mathrm{CH}_{3}$ group for $n=1$. Therefore, on the basis of the observed dependence $V_{\phi}^{0}=f(n)$ for $n=2-5$, we estimate that the value of the partial molar volume of the $\mathrm{CH}_{2}$ - group is $16.01 \mathrm{~cm}^{3} \cdot \mathrm{mol}^{-1}$. This value is very close to that estimated by other authors [20-22], $V_{\mathrm{CH}_{2}}^{0}=15.9-16.0 \mathrm{~cm}^{3} \cdot \mathrm{mol}^{-1}$, and by us [19] $\left(V_{\mathrm{CH}_{2}}^{0}=15.6 \mathrm{~cm}^{3} \cdot \mathrm{mol}^{-1}\right)$ from studies on the apparent molar volumes of sodium salts of the monocarboxylic acids.

Equation 2 for dicarboxylic acids can be rewritten the following form:

$$
V_{\phi}=\beta_{1} V_{\mathrm{H}_{2} \mathrm{~A}(i 1)}+\beta_{2} V_{\mathrm{H}_{2} \mathrm{~A}(i 2)}+\left(1-\beta_{1}-\beta_{2}\right) V_{\mathrm{H}_{2} \mathrm{~A}(u)}
$$

where: $\beta_{1}$ is the fraction of dissociated acid occurring in the form $\mathrm{H}^{+}+\mathrm{HA}^{-}, \beta_{2}$ is the fraction of dissociated electrolyte occurring in the form $2 \mathrm{H}^{+}+\mathrm{A}^{2-}$, and $1-\beta_{1}-\beta_{2}$ is the fraction of the electrolyte in its undissociated form.

Values of $\beta_{1}$ and $\beta_{2}$ can be determined by optimization methods from the equation:

$$
\begin{aligned}
& K_{\mathrm{A} 1}=\frac{1}{K_{\mathrm{D} 1}}=\frac{1-\beta_{1}-\beta_{2}}{\beta_{1}\left(\beta_{1}+2 \beta_{2}\right) c y_{ \pm}^{2}} \\
& K_{\mathrm{A} 2}=\frac{1}{K_{\mathrm{D} 2}}=\frac{\beta_{1}}{\beta_{2}\left(\beta_{1}+2 \beta_{2}\right) c y_{\mathrm{A}^{2-}}} \\
& \ln y \pm=\frac{-A_{\mathrm{DH}} \sqrt{I}}{1+R_{y} B_{\mathrm{DH}} \sqrt{I}} \\
& \ln y_{\mathrm{A}^{2-}}=\frac{-4 A_{\mathrm{DH}} \sqrt{I}}{1+R_{y} B_{\mathrm{DH}} \sqrt{I}}
\end{aligned}
$$

The symbols $K_{\mathrm{D}}$ and $K_{\mathrm{A}}$ indicate, respectively, dissociation and association equilibrium constants.

As in the case of monocarboxylic acids we assumed that $R_{y}=q$, and dissociation constants were taken from Ref. [18]. 


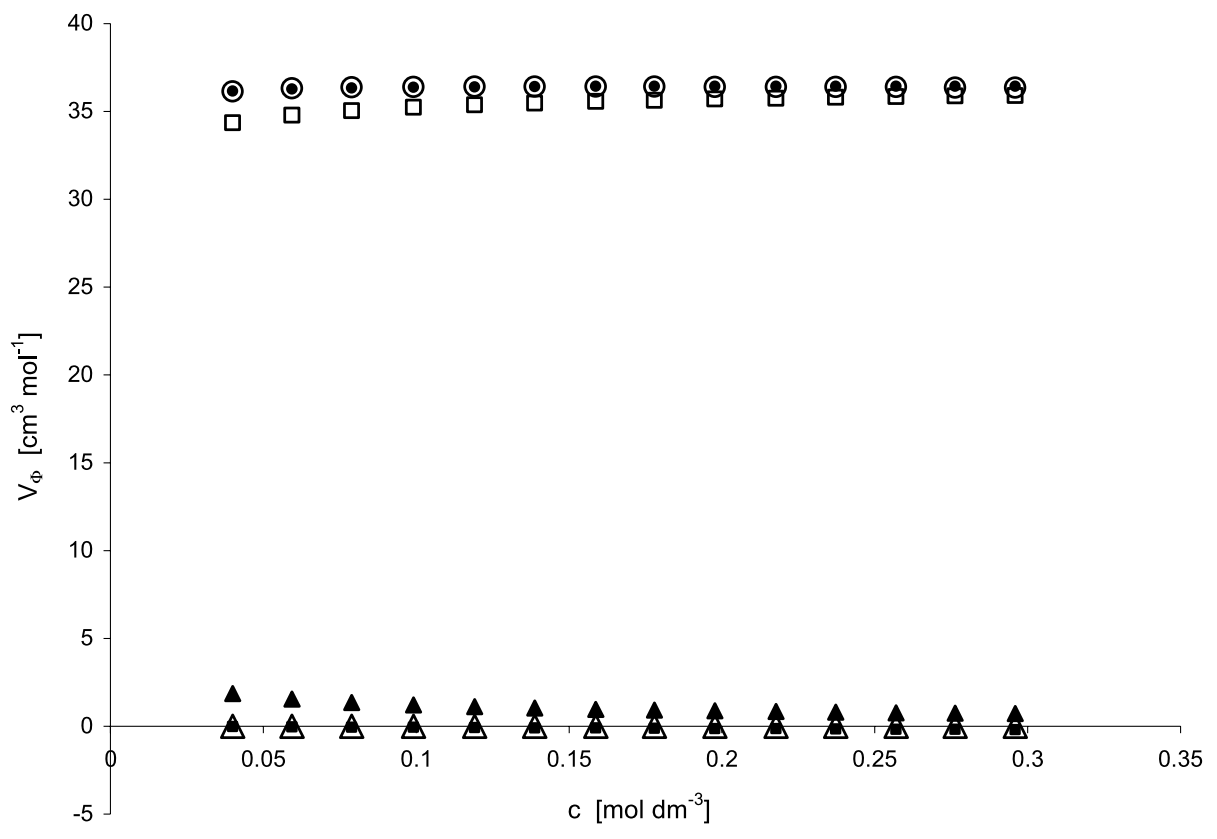

(a)

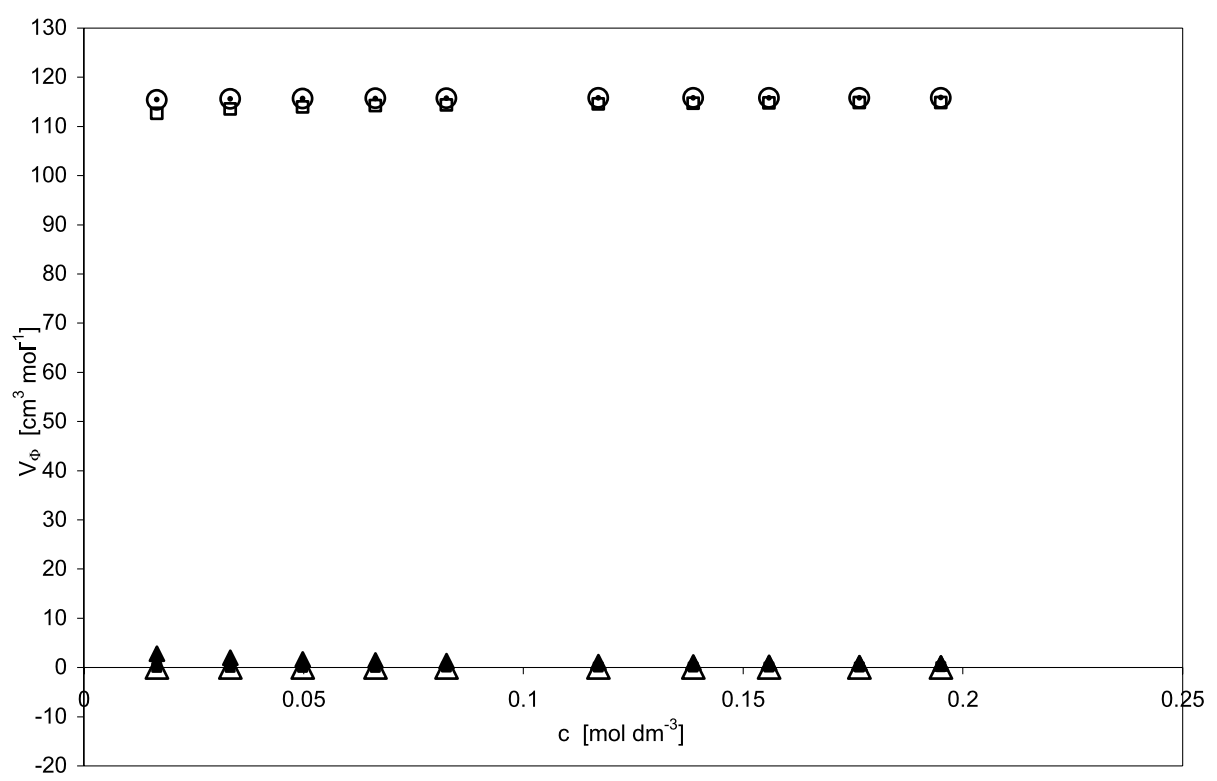

(b)

Fig. 1 The experimental $(\bigcirc)$ and calculated $(\bullet)$ values of $V_{\phi}$ and the values of component terms of Eq. 7: (口) $(1-\beta) V_{\mathrm{HA}(u)}^{0} ;(\mathbf{\Lambda}) \beta V_{\mathrm{HA}(i)}^{0} ;(\mathbf{\square})(1-\beta)^{2} c b_{v(u)} ;(\triangle) \beta S_{v(i)} \sqrt{\beta c}$ for formic acid (a), for caproic acid (b) 
Table 2 Values of $V_{\phi}^{0}$ at $T=298.15 \mathrm{~K}$ for the studied carboxylic acids in the undissociated form

\begin{tabular}{|c|c|c|c|c|c|}
\hline \multicolumn{3}{|c|}{$\mathrm{H}\left(\mathrm{CH}_{2}\right)_{n} \mathrm{COOH}$} & \multicolumn{3}{|c|}{$\mathrm{HOOC}\left(\mathrm{CH}_{2}\right)_{n} \mathrm{COOH}$} \\
\hline $\bar{n}$ & $V_{\phi}^{0}$ & $V_{\phi}^{0}$ lit. & $\bar{n}$ & $V_{\phi}^{0}$ & $V_{\phi}^{0}$ lit. \\
\hline 0 & 36.90 & $34.1[8] ; 34.69$ [5] & 0 & 53.36 & $49.12[6] ; 49.43[9]$ \\
\hline 1 & 52.22 & $52.0[8] ; 51.93[5]$ & 1 & 68.11 & $67.22[6] ; 66.82[9]$ \\
\hline 2 & 67.82 & $67.9[8]$ & 2 & 83.64 & $82.94[6] ; 82.44$ [9] \\
\hline 3 & 84.38 & 84.7 [8]; 84.61 [5] & 3 & 98.99 & $99.14[6] ; 98.98$ [9] \\
\hline 4 & 100.44 & - & 4 & 115.87 & $115.66[6] ; 115.15[9]$ \\
\hline 5 & 115.83 & - & 5 & 131.81 & $131.93[6]$ \\
\hline
\end{tabular}

Table 3 The experimental and calculated values of $V_{\phi}$ and the values of chosen component terms of Eq. 7: $(1-\beta) V_{\mathrm{HA}(u)}^{0}, \beta V_{\mathrm{HA}(i)}^{0},(1-\beta)^{2} c b_{v(u)}$, and $\beta S_{v(i)} \sqrt{\beta c}$

\begin{tabular}{llllll}
\hline$c$ & $V_{\phi}$ & $V_{\phi}$, calculated \\
$\left(\mathrm{cm}^{3} \cdot \mathrm{mol}^{-1}\right)$ & $(1-\beta) V_{\mathrm{HA}(u)}^{0}$ & $\beta V_{\mathrm{HA}(i)}^{0}$ & $(1-\beta)^{2} c b_{v(u)}$ \\
$\left(\mathrm{cm}^{3} \cdot \mathrm{mol}^{-1}\right)$ & & \\
\hline
\end{tabular}

\section{(a) Formic acid}

\begin{tabular}{|c|c|c|c|c|c|}
\hline 0.04001 & 36.13 & 36.16 & 34.35 & 1.85 & -0.02 \\
\hline 0.05934 & 36.31 & 36.27 & 34.78 & 1.54 & -0.04 \\
\hline 0.07897 & 36.36 & 36.33 & 35.05 & 1.35 & -0.05 \\
\hline 0.09912 & 36.37 & 36.37 & 35.24 & 1.21 & -0.06 \\
\hline 0.11912 & 36.40 & 36.40 & 35.37 & 1.11 & -0.08 \\
\hline 0.13871 & 36.41 & 36.41 & 35.48 & 1.03 & -0.09 \\
\hline 0.15870 & 36.41 & 36.43 & 35.57 & 0.97 & -0.10 \\
\hline 0.17791 & 36.41 & 36.43 & 35.64 & 0.92 & -0.12 \\
\hline 0.19774 & 36.42 & 36.44 & 35.70 & 0.87 & -0.13 \\
\hline 0.21773 & 36.43 & 36.44 & 35.75 & 0.84 & -0.14 \\
\hline 0.23719 & 36.43 & 36.44 & 35.80 & 0.80 & -0.16 \\
\hline 0.25697 & 36.44 & 36.44 & 35.84 & 0.77 & -0.17 \\
\hline 0.27623 & 36.44 & 36.43 & 35.87 & 0.75 & -0.18 \\
\hline 0.29592 & 36.45 & 36.43 & 35.91 & 0.72 & -0.20 \\
\hline \multicolumn{6}{|c|}{ (b) Caproic acid } \\
\hline 0.01666 & 115.41 & 115.46 & 112.62 & 2.83 & 0.01 \\
\hline 0.03330 & 115.59 & 115.58 & 113.54 & 2.02 & 0.02 \\
\hline 0.04980 & 115.67 & 115.64 & 113.95 & 1.66 & 0.03 \\
\hline 0.06634 & 115.71 & 115.68 & 114.20 & 1.44 & 0.04 \\
\hline 0.08249 & 115.74 & 115.71 & 114.36 & 1.30 & 0.05 \\
\hline 0.11704 & 115.78 & 115.76 & 114.60 & 1.09 & 0.07 \\
\hline 0.13867 & 115.80 & 115.79 & 114.69 & 1.01 & 0.09 \\
\hline 0.15595 & 115.81 & 115.81 & 114.76 & 0.95 & 0.10 \\
\hline 0.17646 & 115.82 & 115.83 & 114.82 & 0.90 & 0.11 \\
\hline 0.19500 & 115.82 & 115.84 & 114.87 & 0.85 & 0.12 \\
\hline
\end{tabular}

The values of term $\beta S_{v(i)} \sqrt{\beta c}$ are smaller than 0.01 


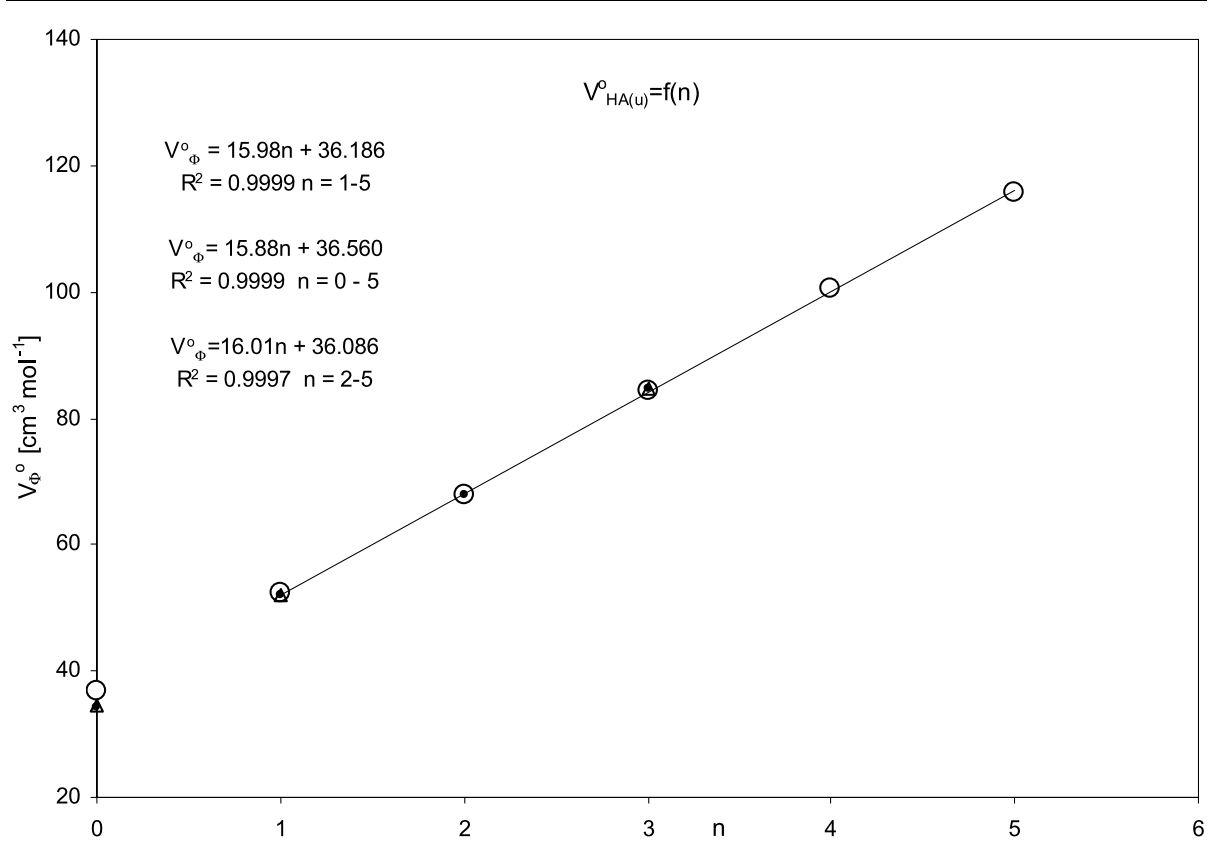

Fig. 2 The dependence of the limiting partial volume of undissociated acids $\left(V_{\phi(\mathrm{HA}, u)}^{0}\right)$ on the number of carbon atoms $(n)$ in the molecules of monocarboxylic acids $\mathrm{H}\left(\mathrm{CH}_{2}\right)_{n} \mathrm{COOH}$ : (O) experimental values; (๑) literature [8]; $(\triangle)$ literature [5]

Values of $\beta_{1}$ and $\beta_{2}$ are reported in Table $1 \mathrm{~b}$. The molar volumes $V_{\mathrm{H}_{2} \mathrm{~A}(i 1)}, V_{\mathrm{H}_{2} \mathrm{~A}(i 2)}$, and $V_{\mathrm{H}_{2} \mathrm{~A}(u)}$ can be expressed by the following equations:

$$
\begin{aligned}
& V_{\mathrm{H}_{2} \mathrm{~A}(i 1)}=V_{\mathrm{H}_{2} \mathrm{~A}(i 1)}^{0}+S_{v \mathrm{H}_{2} \mathrm{~A}(i 1)} \sqrt{\beta_{1} c}+b_{v(i 1)} \beta_{1} c \\
& V_{\mathrm{H}_{2} \mathrm{~A}(i 2)}=V_{\mathrm{H}_{2} \mathrm{~A}(i 2)}^{0}+S_{v \mathrm{H}_{2} \mathrm{~A}(i 2)} \sqrt{\beta_{2} c}+b_{v(i 2)} \beta_{2} c \\
& V_{\mathrm{H}_{2} \mathrm{~A}(i 1)}=V_{\mathrm{H}_{2} \mathrm{~A}(u)}^{0}+b_{v(u)}\left(1-\beta_{1}-\beta_{2}\right)
\end{aligned}
$$

Therefore, Eq. 7 can be rewritten in the following form:

$$
\begin{aligned}
V_{\phi}= & \beta_{1}\left(V_{\mathrm{H}_{2} \mathrm{~A}(i)}^{0}+1.868 \sqrt{\beta_{1} c}+b_{v(i 1)} \beta_{1} c\right)+\beta_{2}\left(V_{\mathrm{H}_{2} \mathrm{~A}(i 2)}^{0}+9.706 \sqrt{\beta_{2} c}\right. \\
& \left.+b_{v(i 2)} \beta_{2} c\right) \beta_{1}\left(V_{\mathrm{H}_{2} \mathrm{~A}(u)}^{0}+b_{v(u)}\left(1-\beta_{1}-\beta_{2}\right)\right)
\end{aligned}
$$

Values of $V_{\mathrm{H}_{2} \mathrm{~A}(i 1)}^{0}$ were calculated using the following equation:

$$
V_{\mathrm{H}_{2} \mathrm{~A}(i 1)}^{0}=V_{\mathrm{NaHA}}^{0}+\left(V_{\mathrm{H}^{+}}^{0}-V_{\mathrm{Na}^{+}}^{0}\right)
$$

Value of $V_{\mathrm{NaHA}}^{0}$, obtained from studies of the apparent molar volumes of monosodium salts of dicarboxylic acids were used these calculations [23]. The value of $V_{\mathrm{H}_{2}}^{0} \mathrm{~A}(i 2)$ was calculated similarly:

$$
V_{\mathrm{H}_{2} \mathrm{~A}(i 2)}^{0}=V_{\mathrm{Na}_{2} \mathrm{~A}}^{0}+2\left(V_{\mathrm{H}^{+}}^{0}-V_{\mathrm{Na}^{+}}^{0}\right)
$$




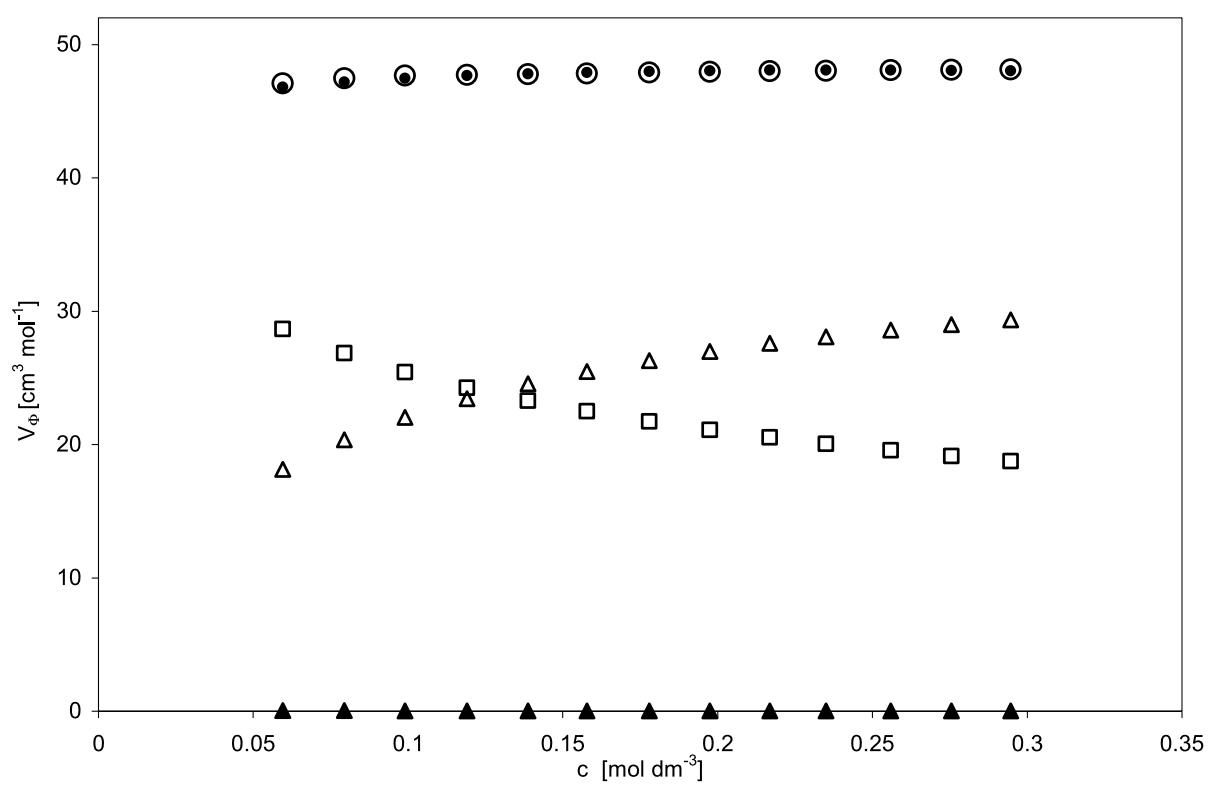

(a)

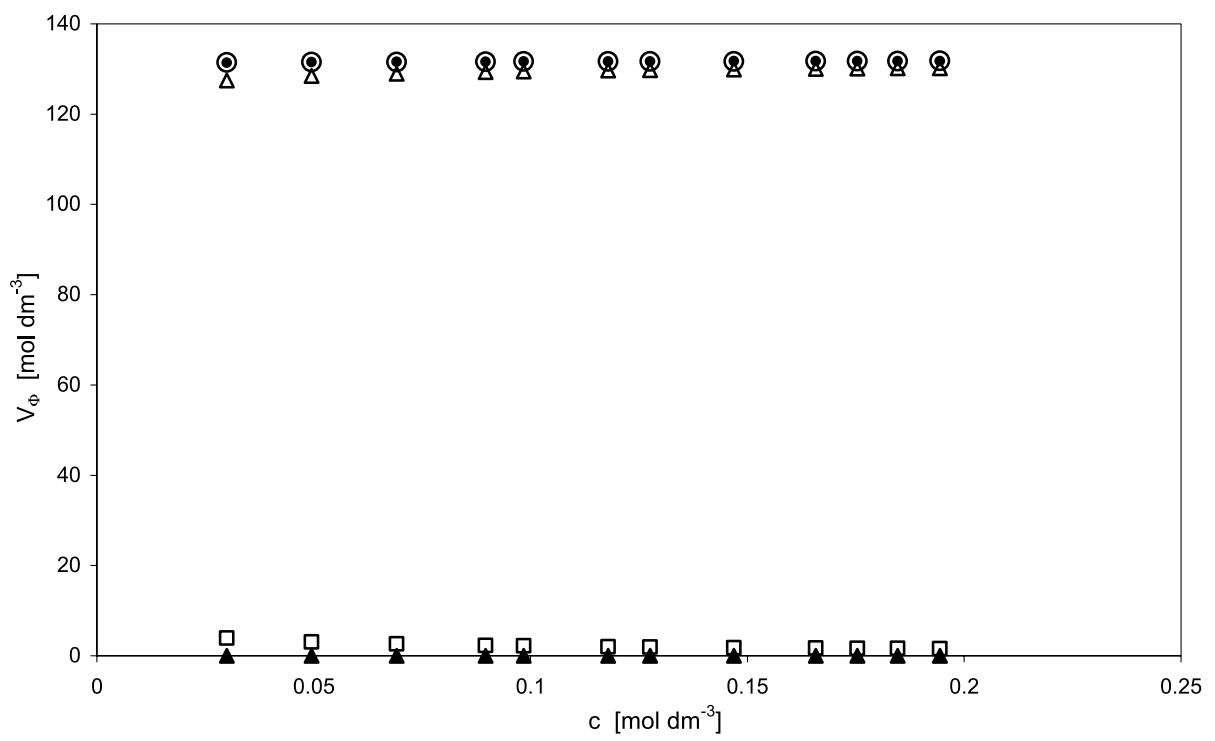

(b)

Fig. 3 The experimental $(O)$ and calculated values $(\bullet)$ of $V_{\phi}$ and the values of terms of Eq. 7: (口) $\beta_{1} V_{\mathrm{H}_{2} \mathrm{~A}_{(i 1)}}^{0} ;(\boldsymbol{\Delta}) \beta_{2} V_{\mathrm{H}_{2} \mathrm{~A}_{(i 2)}}^{0} ;(\triangle)\left(1-\beta_{1}-\beta_{2}\right) V_{\mathrm{H}_{2} \mathrm{~A}_{(u)}}^{0}$ for oxalic acid (a), for pimelic acid (b)

using the values of $V_{\mathrm{Na}_{2} \mathrm{HA}}^{0}$ reported in our earlier work [19]. The values of component terms: $\beta_{1} V_{\mathrm{H}_{2} \mathrm{~A}(i 1)}^{0}, \beta_{2} V_{\mathrm{H}_{2} \mathrm{~A}(i 2)}^{0}$ as well as values of $\beta_{1} 1.868 \sqrt{\beta_{1} c}$, and $\beta_{2} 9.706 \sqrt{\beta_{2} c}$ are known. Values of $b_{v(i 1)}, b_{v(i 2)}, b_{v(u)}$ and $V_{\mathrm{H}_{2} \mathrm{~A}(u)}^{0}$ remain unknowns in Eq. 16. 
Table 4 The experimental and calculated values $V_{\phi}$ and the values of chosen components of Eq. 7: $\beta_{1} V_{\mathrm{H}_{2} \mathrm{~A}_{(i 1)}}^{0}, \beta_{2} V_{\mathrm{H}_{2} \mathrm{~A}_{(i 2)}}^{0}$, and $\left(1-\beta_{1}-\beta_{2}\right) V_{\mathrm{H}_{2} \mathrm{~A}_{(u)}}^{0}$

\begin{tabular}{llllll}
\hline$c$ & $V_{\phi}$ & $V_{\phi}$, calculated & $\left(1-\beta_{1}-\beta_{2}\right) V_{\mathrm{H}_{2} \mathrm{~A}_{(u)}}^{0}$ & $\beta_{1} V_{\mathrm{H}_{2} \mathrm{~A}_{(i 1)}}^{0}$ & $\beta_{2} V_{\mathrm{H}_{2} \mathrm{~A}_{(i 2)}}$ \\
$\left(\mathrm{mol} \cdot \mathrm{dm}^{-3}\right)$ & $\left(\mathrm{cm}^{3} \cdot \mathrm{mol}^{-1}\right)$ & $\left(\mathrm{cm}^{3} \cdot \mathrm{mol}^{-1}\right)$ & & \\
\hline
\end{tabular}

\section{(a) Oxalic acid}

$\begin{array}{llllll}0.05957 & 47.08 & 46.80 & 18.13 & 28.67 & 0.049 \\ 0.07941 & 47.47 & 47.19 & 20.35 & 26.84 & 0.040 \\ 0.09898 & 47.66 & 47.46 & 22.04 & 25.44 & 0.034 \\ 0.11899 & 47.72 & 47.66 & 23.43 & 24.26 & 0.030 \\ 0.13875 & 47.78 & 47.81 & 24.55 & 23.29 & 0.026 \\ 0.15782 & 47.83 & 47.91 & 25.47 & 22.48 & 0.024 \\ 0.17794 & 47.89 & 47.99 & 26.29 & 21.74 & 0.022 \\ 0.19752 & 47.95 & 48.04 & 26.99 & 21.10 & 0.020 \\ 0.21687 & 48.00 & 48.06 & 27.58 & 20.54 & 0.019 \\ 0.23499 & 48.03 & 48.08 & 28.08 & 20.06 & 0.018 \\ 0.25588 & 48.08 & 48.07 & 28.58 & 19.56 & 0.017 \\ 0.27549 & 48.11 & 48.06 & 29.00 & 19.13 & 0.016 \\ 0.29467 & 48.13 & 48.03 & 29.36 & 18.74 & 0.015\end{array}$

(b) Pimelic acid

\begin{tabular}{llllll}
0.02994 & 131.42 & 131.39 & 127.48 & 3.89 & 0.015 \\
0.04949 & 131.49 & 131.50 & 128.43 & 3.06 & 0.009 \\
0.06910 & 131.55 & 131.56 & 128.95 & 2.60 & 0.007 \\
0.08963 & 131.61 & 131.61 & 129.31 & 2.30 & 0.005 \\
0.09845 & 131.64 & 131.63 & 129.43 & 2.19 & 0.005 \\
0.11788 & 131.65 & 131.67 & 129.65 & 2.01 & 0.004 \\
0.12756 & 131.68 & 131.68 & 129.74 & 1.94 & 0.004 \\
0.14689 & 131.70 & 131.71 & 129.90 & 1.81 & 0.003 \\
0.16581 & 131.73 & 131.73 & 130.03 & 1.71 & 0.003 \\
0.17539 & 131.76 & 131.75 & 130.08 & 1.66 & 0.003 \\
0.18469 & 131.76 & 131.76 & 130.14 & 1.62 & 0.003 \\
0.19440 & 131.77 & 131.77 & 130.19 & 1.58 & 0.002 \\
\hline
\end{tabular}

The component terms of Eq. 16 linked with $b_{v(i 1)}, b_{v(i 2)}$ as $\beta_{1}^{2} b_{v(i 1)} c$ and $\beta_{2}^{2} b_{v(i 2)} c$, are in general neglected since they are small in comparison to the values of $V_{\phi}$. An exception occurs in the case of oxalic acid where the $\beta_{1}^{2} b_{v(i 1)} c$ term of the equation has values within 0.03-0.04. Therefore, values $b_{v(i 1)}$ accepted for oxalic acid have been set equal to the analogous values for HCOO-COONa [23]. This approximation seems to be better than the assumption that $b_{v(i 1)}=0$.

Figures $3 \mathrm{a}$ and $3 \mathrm{~b}$ show the concentration dependences of the individual terms of Eq. 16. As is seen at Fig. 3a and Table 4a for oxalic acid, values of $\beta_{1} V_{\mathrm{H}_{2} \mathrm{~A}(i 1)}^{0}$ are comparable with the term representing the undissociated portion of the acid $\left(1-\beta_{1}-\beta_{2}\right) V_{\mathrm{H}_{2} \mathrm{~A}(u)}^{0}$ over the studied concentration range. For pimelic acid (Fig. $3 \mathrm{~b}$ and Table 4b), the contribution of the $\beta_{1} V_{\mathrm{H}_{2} \mathrm{~A}(i 1)}^{0}$ term to $V_{\phi}$ is small. It results of course from the fact that oxalic acid is more 


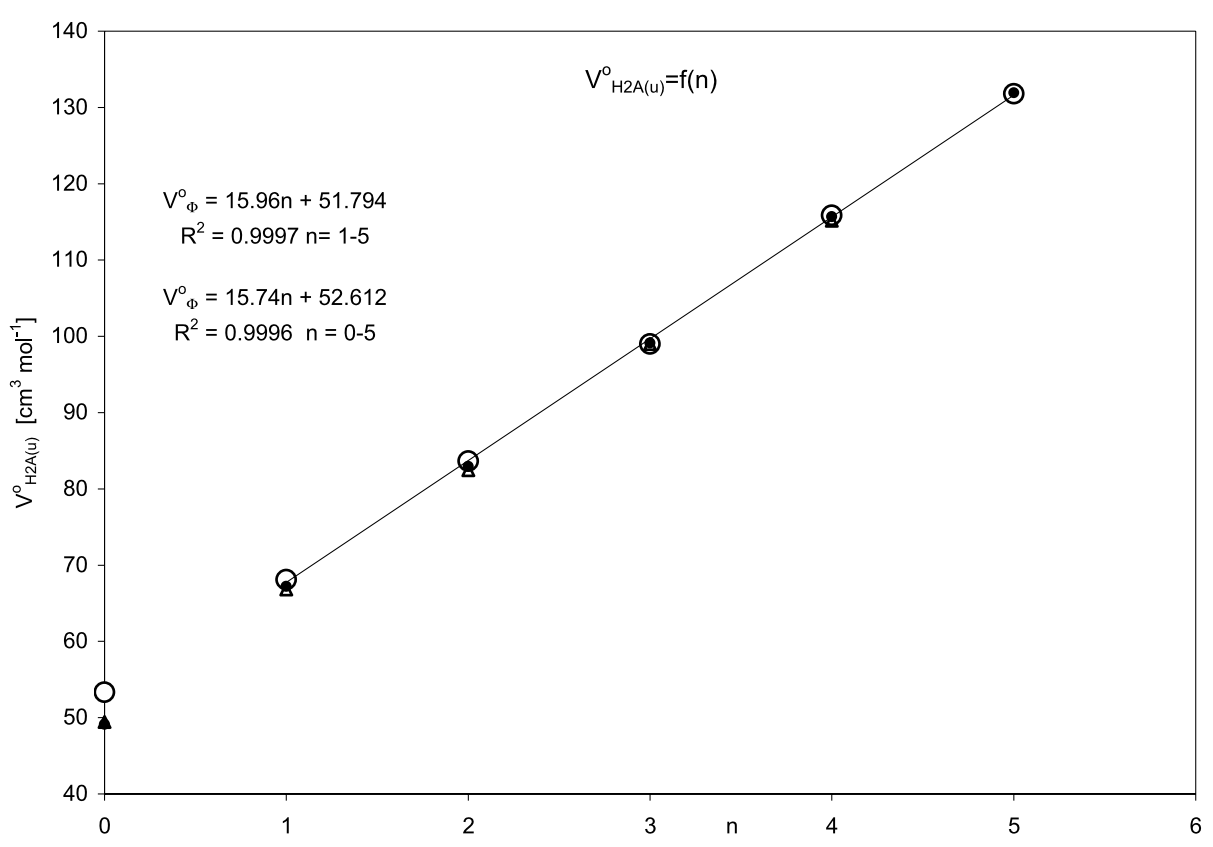

Fig. 4 The dependence of the limiting partial volume of undissociated acids $\left(V_{\mathrm{H}_{2} \mathrm{~A}(u)}^{0}\right)$ as a function of the number of carbon atoms $(n)$ in the molecules of dicarboxylic acids $\mathrm{HOOC}\left(\mathrm{CH}_{2}\right)_{n} \mathrm{COOH}$ : (O) experimental values; $(\bigcirc)$ literature [6]; $(\triangle)$ literature [9]

dissociated. Values for the $\beta_{2} V_{\mathrm{H}_{2} \mathrm{~A}_{(i 2)}}^{0}$ term for the studied acids are comparable to or much less than the errors of $V_{\phi}$ (oxalic acid).

While choosing the method for determining the value of $V_{\mathrm{H}_{2} \mathrm{~A}(u)}^{0}$ for dicarboxylic acids $\left(\mathrm{CH}_{2}\right)_{n}(\mathrm{COOH})_{2}$, it is necessary to take into account the distinct increase of the value of $\beta_{1}$ (and thereby the contribution of the component term $\beta_{1} V_{\mathrm{H}_{2} \mathrm{~A}(i 1)}^{0}$ ) when $n=0$ (and for $n=1,2)$. Values of $V_{\mathrm{H}_{2}}^{0} \mathrm{~A}(u)$ determined by the nonlinear least-squares method are reported in Table 2.

It is observed that for carboxylic acids with $n=3-5$, consistency among the results of Høiland [6], Sipkes [9], and our results are good, for $n=2$ it is slightly worse, whereas for $n=0$ (oxalic acid) the divergence reaches approximately $4 \mathrm{~cm}^{3} \cdot \mathrm{mol}^{-1}$. Høiland omitted the second dissociation step in Eq. 16 as quantitatively inessential and, after examining the King's method, he presented Eq. 16 in the alternative form:

$$
V_{\phi}^{\prime \prime}=V_{\phi}-\beta_{1}\left(\Delta V_{1}\right)-\beta_{1} 1.868 \sqrt{\beta_{1} c}=V_{\mathrm{H}_{2} \mathrm{~A}(u)}^{0}+\left(1+\beta_{1}\right)^{2} b_{v(u)} c
$$

where:

$$
\Delta V_{1}=V_{\mathrm{H}_{2} \mathrm{~A}(i 1)}^{0}-V_{\mathrm{H}_{2} \mathrm{~A}(u)}^{0}
$$

According to Høiland [6], the left side of the Eq. 17 differs slightly from $V_{\phi}$. Høiland evaluated these differences as being small $\left(0.1-0.5 \mathrm{~cm}^{3} \cdot \mathrm{mol}^{-1}\right)$ for dissociation constants ranging from $10^{-4}$ to $10^{-5}$. However, for oxalic acid such differences cannot be neglected.

It is also worth mentioning that according to Høiland, values of $V_{\phi(u)}^{0}$ and $\Delta V_{i}$ could be burdened with a large error. After taking into account the value $\Delta V_{1}=-6.7 \mathrm{~cm}^{3} \cdot \mathrm{mol}^{-1}$ estimated by Høiland and values $\beta_{1}$ for this acid included in Table 1 , it is clear that differences 
between values of $V_{\phi}^{\prime \prime}-V_{\phi}$ must be considerably greater since only the $\beta_{1} \Delta V_{1}$ term reaches a value of a few $\mathrm{cm}^{3} \cdot \mathrm{mol}^{-1}$. The same concern also applies to the acids $\left(\mathrm{CH}_{2}\right)_{n}(\mathrm{COOH})_{2}$ with $n=1$ and $n=2$, although to a smaller degree. The above mentioned comments may be useful for explaining the differences between values of $V_{\mathrm{H}_{2} \mathrm{~A}(u)}^{0}$ estimated in the present work and Høiland's results.

Similar comments apply to the consistency with Sijpkes [9] data. Sijpkes treated $\Delta V_{1}$ as the chosen parameter in Eq. 17 and obtained its value using least-squares analysis. However, values $\Delta V_{1}$ that he determined differ considerably from the results reported by Høiland. Such differences are particularly noticeable for acids $(n>0)$ for which the approximations used by Høiland are very justified.

The dependence of $V_{\phi, \mathrm{H}_{2} \mathrm{~A}(u)}^{0}$ on the number of carbon atoms $(n)$ in the hydrocarbon chain for $n=1-5$ is shown in Fig. 4. It is linear indicating that the molar volume of the $-\mathrm{CH}_{2}-$ group is approximately equal to $15.96 \mathrm{~cm}^{3} \cdot \mathrm{mol}^{-1}$. This value is very close to the value obtained in the present work for monocarboxylic acids.

Knowledge of the value $\mathrm{H}_{2} \mathrm{~A}_{(i 1)}$ [23] is necessary for a detailed analysis of the apparent molar volumes of a dicarboxylic acid. This value can be determined from results of studies of monosodium salts (NaHA) of dicarboxylic acids after taking into account all equilibria occurring in the solutions. This will be a subject of our future studies.

Open Access This article is distributed under the terms of the Creative Commons Attribution Noncommercial License which permits any noncommercial use, distribution, and reproduction in any medium, provided the original author(s) and source are credited.

\section{References}

1. Chmielewska, A., Bald, A.: Viscosimetric studies of aqueous solutions of dicarboxylic acids. J. Mol. Liq. 137, 116-121 (2008)

2. Chmielewska, A., Wypych-Stasiewicz, A., Bald, A.: Viscosimetric studies of aqueous solutions of monosodium salts of dicarboxylic acids. J. Mol. Liq. 136, 11-14 (2007)

3. Chmielewska, A., Wypych-Stasiewicz, A., Bald, A.: Viscosity of aqueous solutions of monocarboxylic acids. J. Mol. Liq. 130, 42-47 (2007)

4. Chmielewska, A., Wypych-Stasiewicz, A., Bald, A.: Viscosimetric studies of aqueous solutions of salts of carboxylic acids. J. Mol. Liq. 122, 110-155 (2005)

5. King, E.J.: Volume changes for ionization of formic, acetic, and $n$-butyric acids and the glycinium ion in aqueous solution at $25^{\circ} \mathrm{C}$. J. Phys. Chem. 73, 1220-1232 (1969)

6. Høiland, H.: Volumes of ionization of dicarboxylic acids in aqueous solution from density measurements at $25^{\circ}$ C. J. Chem. Soc., Faraday Trans. 71, 797-802 (1975)

7. Patterson, B.A., Woolley, E.M.: Thermodynamics of proton dissociations from aqueous citric acid: Apparent molar volumes and apparent molar heat capacities of citric acid and its sodium salts at the pressure $0.35 \mathrm{MPa}$ and at temperatures from $278.15 \mathrm{~K}$ to $393.15 \mathrm{~K}$. J. Chem. Therm. 33, 1735-1764 (2001)

8. Hamann, S.D., Lim, S.C.: The volume on ionization of weak electrolytes. Aust. J. Chem. 7, 329-324 (1954)

9. Sijpkes, A.H., Van Rossum, P., Raad, J.S., Somsen, G.: Heat capacities and volumes of some polybasic carboxylic acids in water at 298.15 K. J. Chem. Thermodyn. 21, 1061-1067 (1989)

10. Apelblat, A., Manzurola, E.: Solubility of ascorbic, 2-furancarboxylic, glutaric, pimelic, salicylic, and $o$-phthalic acids in water from 279.15 to $342.15 \mathrm{~K}$, and apparent molar volumes of ascorbic, glutaric, and pimelic acids in water at 298.15 K. J. Chem. Thermodyn. 21, 1005-1008 (1989)

11. Ben-Hamo, M., Apelblat, A., Manzurola, E.: Volumetric properties of aqueous solutions of glutaric acid. J. Chem. Thermodyn. 39, 1071-1076 (2007)

12. McRae, B.R., Patterson, B.A., Origlia-Luster, M.L., Sorenson, E.C., Woolley, E.M.: Thermodynamics of proton dissociation from aqueous 1-propanoic and 1-butanoic acids at temperatures $278.15 \leq$ $(T / \mathrm{K}) \leq 393.15$ and pressure $p=0.35 \mathrm{MPa}$ : apparent molar volumes and apparent molar heat capacities of aqueous solutions of the acids and their sodium salts. J. Chem. Thermodyn. 35, 301-329 (2003)

13. Manzurola, E., Apelblat, A.: Apparent molar volumes of citric, tartaric, malic, succinic, maleic and acetic acids in water at 298.15 K. J. Chem. Thermodyn. 14, 579-584 (1985) 
14. Apelblat, A., Manzurola, A.: Excess molar volumes of formic acid + water, acetic acid + water and propionic acid + water at 288.15, 298.15 and 308.15 K. Fluid Phase Equilib. 32, 163-193 (1987)

15. Apelblat, A., Manzurola, E.: Apparent molar volumes of organic acids and salts in water at $298.15 \mathrm{~K}$. Fluid Phase Equilib. 60, 157-171 (1990)

16. Redlich, O., Meyer, D.M.: The molal volumes of electrolytes. Chem. Rev. 64, 221-227 (1964)

17. Millero, F.J.: The molal volumes of electrolytes. Chem. Rev. 71, 147-176 (1971)

18. Apelblat, A.: Dissociation constants and limiting conductances of organic acid in water. J. Mol. Liq. 95, 99-145 (2002)

19. Kinart, Z., Bald, A.: Apparent molal volumes of sodium salts of some aliphatic carboxylic acids in water at 298.15. Phys. Chem. Liquids, doi:10.1080/00319101003646579 (in press)

20. Høiland, H.: Additivity relations of partial molal volumes in carboxylic acid series. Acta Chem. Scand. A 28, 699-700 (1974)

21. Millero, F.J., Lo Surdo, A., Shin, C.: The apparent molal volumes and adiabatic compressibilities of aqueous amino acids at $25^{\circ} \mathrm{C}$. J. Phys. Chem. 82, 784-792 (1978)

22. Jolicour, C., Lacroix, G.: Thermodynamic properties of aqueous organic solutes in relation to their structure. Part III. Apparent molal volumes and heat capacities of low molecular weight alcohols and polyols at $25^{\circ}$ C. Can. J. Chem. 54, 624-631 (1976)

23. Bald, A., Kinart, Z.: Private communication 